\title{
EDITORIAL
}

\section{EL DESAFÍO DE LA VINCULACIÓN CON EL MEDIO EN TIEMPOS DE PANDEMIA COVID-19}

\author{
THE CHALLENGE OF LINKING WITH THE \\ ENVIRONMENT IN TIMES OF PANDEMIC COVID-19
}

\author{
Mg. Fabiola Arriagada Gallardo \\ DireCTORA DE VINCULACIÓN CON EL MEDIO \\ Facultad de Enfermería, Universidad de Concepción \\ ORCID: https://orcid.org/0000-0003-4191-1380 \\ Email: faarriagada@udec.cl
}

En diciembre del año 2019 el Gobierno chino informa que hay 27 casos de personas afectadas por un virus desconocido y que cursan un síndrome respiratorio agudo, confirmando posteriormente la relación laboral de estas personas con el Mercado de animales exóticos en Wuhan. Este es el comienzo de la Pandemia SARS-CoV-2 que impacta al mundo de manera transversal, no solo en el ámbito de la salud, sino que también en lo social, económico y emocional $^{(1)}$.

En Chile, este virus traspasa nuestras fronteras el día 3 de marzo de 2020, detectándose el primer caso y marcando el inicio de la transformación de los quehaceres cotidianos debido al confinamiento y el distanciamiento social. Nuestro hogar se transformó y paso a ser el lugar de trabajo, la sala de clase del colegio de los niños y el aula de las universidades para los jóvenes. Los encuentros con nuestros familiares y amigos ya no serían al aire libre o en algún lugar público, sino que a través de las pantallas de dispositivos de comunicación ${ }^{(2)}$.

En este contexto, la Universidad de Concepción no quedó ajena a este proceso, y debió continuar con el desarrollo de un gran número de sus actividades, ahora a distancia, siendo el teletrabajo la modalidad con la que las diferentes áreas tuvieron que sustentar el quehacer universitario: formación de pre y posgrado, investigación, gestión institucional y vinculación con el medio.

La vinculación con el medio es un eje universitario cuya función es de vital importancia, ya que permite la relación de la institución con la comunidad nacional e internacional, ejecutando actividades desde y hacia la comunidad, que permiten orientar a la población respecto a diversos aspectos que esta requiera. Con ello contribuye de manera eficaz a lograr presencia y visibilidad del quehacer universitario ${ }^{(3)}$ porque en la tarea de vincularse con el medio se desarrolla el contacto genuino con la comunidad, generándose lazos que favorecen la cercanía, la comunicación y la retroalimentación necesaria para dar lugar a las propuestas y asesorías que, desde la academia, dan solución a múltiples problemas y desafíos que allí se enfrentan. 
¿Pero cómo logramos desarrollar la vinculación con el medio en tiempos de pandemia? ¿Cómo la Universidad, comprometida con su responsabilidad social, logra el impacto necesario para apoyar a la comunidad, aun en tiempos de crisis?, estas son interrogantes que no se pueden dilucidar por completo de manera anticipada, pero sí se puede observar la búsqueda de estrategias para seguir con las tareas de informar, educar, respaldar y proteger a toda la comunidad en tiempos de pandemia.

La tecnología, en estos últimos meses, se ha transformado en protagonista como herramienta de comunicación en diversas actividades; y en Chile, al mismo tiempo que se logra aumentar el uso de plataformas y videoconferencias en un $80 \%$, también se disminuye la velocidad de las redes, manifestándose, en algunos sectores, una brecha tecnológica por causas económicas o de ruralidad, que impide mantener un servicio adecuado de conectividad y acceder a la información, los contenidos educativos y beneficios gubernamentales ${ }^{(4)}$. A pesar de esto, la tecnología y el uso de plataformas virtuales han sido un aporte para la población que ha requerido apoyo por el aislamiento social, en áreas como la educación, la compra de insumos básicos, la sociabilización con familiares y amigos, asistencia de empresas, la salud y el teletrabajo ${ }^{(5)}$.

Las instituciones de educación han tenido que ampliar sus redes tecnológicas para cubrir las innumerables actividades y demandas que se deben seguir desarrollando a nivel regional, nacional e internacional y la Universidad de Concepción no ha estado ajena a este vertiginoso desafío que, poco a poco, se transforma en crecimiento institucional, porque el uso de TIC y la ampliación del uso de plataformas virtuales están a disposición de toda la comunidad universitaria, brindando la posibilidad de tener contacto estrecho entre distintos grupos de trabajo y de estudiantes.

Estas plataformas de comunicación han sido claves para que la vinculación con el medio se continúe ejecutando, particularmente en la Facultad de Enfermería. Como unidad académica asociada al cuidado de la salud de la población, la vinculación le permite sustentar sus pilares fundamentales, la responsabilidad social y el compromiso con la comunidad de manera continua, que resultan esenciales en esta etapa de crisis sanitaria nacional y mundial. Así, desde el primer día en que tuvimos que quedarnos en casa, la Facultad se volcó a realizar diferentes actividades que potenciaron su vínculo con el medio, llegando a ser un aporte indiscutible en tiempos de pandemia.

Múltiples son las actividades realizadas en estos últimos meses, dirigidas a grupos de riesgo vulnerables como las personas con enfermedades crónicas u otros tan importantes como los cuidadores de adultos mayores, de niños o discapacitados. Los propios académicos han sido protagonistas de diversas modalidades de vinculación virtual: videos informativos, conferencias sincrónicas, conversatorios, consejería y capacitación en medios de comunicación locales como diarios, radio y televisión. Importante ha sido el vínculo con los establecimientos sanitarios, a los cuales se les han impartido cursos dirigidos a profesionales de la salud que se han integrado a la primera línea y a las nuevas dependencias habilitadas y reconvertidas en los hospitales de la zona y a los cuales se necesitaba capacitar para brindar atención y cuidados seguros en tiempos de Covid-19. Complementario a ello, se ha potenciado el uso de redes sociales como Facebook, Instagram y Twitter, para difundir, con fines preventivos, información relevante de datos, cifras y aspectos educativos del SARS-CoV-2.

Esta pandemia, que ha provocado una crisis sanitaria sin precedentes y no se sabe por cuánto tiempo se prolongará, ha impactado en las poblaciones más vulnerables que no pueden tener acceso a los medios virtuales y frente a ello nuestro país, al igual que muchos otros, no 
estaba preparado para cubrir estas demandas. Aun así, las crisis siempre son una oportunidad y lo que se ha implementado en estos últimos meses en la Universidad de Concepción y en la Facultad de Enfermería demuestra que es posible emprender nuevos caminos e implementar nuevas herramientas educativas para la comunidad.

Importante ha sido entender que para vincularse con la comunidad la presencialidad acostumbrada no es un requisito, debe transformarse y convertirse en una alternativa de comunicación virtual accesible y sensible a las necesidades de su entorno. En el contexto de la crisis sanitaria, estos esfuerzos resultan más valiosos que nunca, y deben multiplicarse ${ }^{(6)}$.

\section{REFERENCIAS}

1. Huang X, Wei F, Hu L, Wen L, Chen K. Epidemiología y características clínicas de COVID-19. Arch Iran Med [Internet]. 2020 [citado 18 jun 2020]; 23(4): 268-271. Disponible en: https:// pubmed.ncbi.nlm.nih.gov/32271601/

2. Rodríguez-Morales AJ, Rodríguez-Morales AG, Méndez CA, Hernández-Botero S. Tracing New Clinical Manifestations in Patients with COVID-19 in Chile and Its Potential Relationship with the SARS-CoV-2 Divergence. Curr Trop Med Rep [Internet]. 2020 abr 18 [citado 18 jun 2020]; 1-4. Disponible en: https://pubmed.ncbi.nlm.nih.gov/32313804/

3. Tommasino H. Vinculación con el medio y territorio. Heterogeneidad de modelos, prácticas y sentidos en las universidades chilenas. Revista F@ro [Internet]. 2018 [citado 18 jun 2020]; 2(28): 107-108. Disponible en: http://www.revistafaro.cl/index.php/Faro/article/view/563

4. Katz R, Jung J, Callorda F. El estado de la digitalización de América Latina frente a la pandemia del COVID-19 [Internet]. Corporación Andina de Fomento CAF. 2020 abr [citado 18 jun 2020]; 39 p. Disponible en: https://scioteca.caf.com/handle/123456789/1540

5. Perticara M, Tejada M. Sobre vulnerabilidad y teletrabajo durante la pandemia. OE [Internet]. 2020 abr [citado 18 jun 2020]; 144: 4-5. Disponible en: https://www.observatorioeconomico.cl/ index.php/oe/article/view/365

6. Centro Interuniversitario para el Desarrollo (CINDA). Universidades CINDA se involucran en el combate al Covid-19 [Internet]. Noticias, Santiago: Chile 2020 [citado 18 jul 2020]. Disponible en: https://cinda.cl/noticias/universidades-cinda-se-involucran-en-el-combate-al-covid-19/ 